\title{
Laparoscopic Transabdominal Cerclage
}

\author{
Marilien Gebruers $^{1}$, Yves Jacquemyn ${ }^{1}$, Jérôme Cornette ${ }^{2}$ \\ ${ }^{1}$ Department of Obstetrics and Gynecology, University Hospital Antwerp (UZA), Antwerp, Belgium \\ ${ }^{2}$ Department of Obstetrics, Erasmus Medical Centre, Rotterdam, The Netherlands \\ Email: Yves.Jacquemyn@uza.be, mariel_gebruers@hotmail.com
}

Received February 20, 2013; revised March 22, 2013; accepted March 31, 2013

Copyright (C) 2013 Marilien Gebruers et al. This is an open access article distributed under the Creative Commons Attribution License, which permits unrestricted use, distribution, and reproduction in any medium, provided the original work is properly cited.

\begin{abstract}
Cervical insufficiency is seen in $0.1 \%$ - $1 \%$ of all pregnancies and classical treatment involves vaginal cerclage. In some conditions, such as an extremely short, deformed or absent cervix, surgery needs to be done by transabdominal approach. We use a simplified technique for laparoscopic transabdominal cerclage compared to the technique described in previous studies. Furthermore, we give a review on the literature published on this subject. We have a case series of 12 patients operated in a non-pregnant state with previously failed vaginal cerclage $(n=4)$ or in which a vaginal approach appeared to be impossible due to a history of cervical surgery $(n=8)$. Minor complication of vaginal erosion of the cerclage tape was described in 2 cases. Comparable studies of transabdominal cerclage via laparotomy or laparoscopy could not show any difference in obstetric outcome. Several studies mentioned the advantages of the laparoscopic approach (short hospitalisation, fast recovery, high placement of the suture, ...) and no complications were described. Transabdominal cerclage performed by laparoscopy seems to be a feasible technique in cases transvaginal cerclage fails or is technically impossible.
\end{abstract}

Keywords: Cerclage; Cervical Insufficiency; Laparoscopy

\section{Introduction}

Part of preterm deliveries is caused by cervical insufficiency $(0.1 \%-1 \%$ of all pregnancies) [1]. Cervical insufficiency is defined as "a painless dilatation of the cervix resulting in bulging or ruptured membranes and midtrimester miscarriage" [2]. Surgical treatment involves a cervical cerclage, first described in 1955 by Lash and Lash and little later by Shirodkar. The currently most frequently used and most simple technique of transvaginal cerclage (TVC), a purse string suture around the body of the cervix, was described in 1957 by McDonald [3]. Cerclage can be performed both in the pregnant and the non-pregnant state. In some conditions, such as an extremely short, deformed or absent cervix, the vaginal approach does not allow placement of the cerclage. The first transabdominal cerclage (TAC) by laparotomy was reported in 1965 by Benson et al. [4]. With the rise of laparoscopic possibilities, laparoscopic TAC became an option [5]. This technique is optimally performed in the non-pregnant state and has the advantage of shorter hospitalization and faster recovery. A possible additional indication is combined laparoscopic cerclage with trachelectomy in the conservative management of early stage cervical cancer in young woman [6-8]. We present a sim- plified technique we use and a review of the available literature.

\section{Methods}

The technique we used is a simplified modification of that described by several authors [1,5]. The operation was always done in a non-pregnant state.

Preparation:

Under general anaesthesia the patient is placed in dorsal lithotomy position. After inserting a Foley catheter in the urinary bladder and an uterine manipulator, a subumbilical incision for the laparoscope is made by using the closed Verres technique. Two more trocars at the right and left lower abdominal quadrants were placed.

Step 1: Development of the paravesical and vesicouterine spaces

A solution with vasopressine (Vasopressine ${ }^{\mathrm{R}} 20$ Units/ $1 \mathrm{ml}$, American Regent Inc., Shirly, New York, diluted in $50 \mathrm{cc} 0.9 \% \mathrm{NaCl}$ ) is injected under the peritoneum of the uterovesical reflection and lateral of the lower uterus. This facilitates the bloodless separation of the bladder from the cervix.

Step 2: Creation of windows in the broad ligament

Subsequently branches of the uterine artery and vein 
are identified, so that the cardinal ligament can be perforated from anterior to posterior by a straight atraumatic clamp in an avascular area on the median side of the uterine vessels on both sites. The instrument is guided in such a way that the perforation at the posterior side is medially located from the uterosacral ligament.

Step 3: Placement of suture material through the broad ligament windows

At this point, our technique differs slightly from that described by other authors [1,5]. A polyester tape $(5 \mathrm{~mm}$ width Mersilene ${ }^{\mathrm{R}}$, Ethicon, Johnson and Johnson), the needles removed, is passed into the pelvis and pulled through the holes with both free ends of the tape at the anterior side. Because the windows are medially located from the uterosacral ligament on both sides and a small purchase of cervical tissue is taken, there is no need for further anchoring of the suture on the uterus. Therefore, the needles are redundant and can be removed.

Step 4: Securing the cerclage by knots

Finally three knots are made in the tape at the anterior side of the uterus resulting in a tension free loop around the cervix above the insertion of the uterosacral ligament. We do not close the peritoneum over the knot (Figure 1).

No perioperative antibiotics ware administered and all the patients could be discharged home the same day.

We have used this technique in patients with previously failed vaginal cerclage $(n=4)$ or in whom due to previous cervical surgery vaginal surgery was deemed impossible $(\mathrm{n}=8)$.

In one patient who had previously undergone several laparotomies, during dissection the bladder was perforated. We decided to perform a laparotomy, close the bladder and subsequently place the cerclage during the latter procedure. In one patient who had undergone complete amputation of the cervix, at 1 month, postoperative the cerclage was found to be visible intravaginally. It was decided to leave this in situ.

\section{Discussion}

Our small case series of 12 patients describes a technique of laparoscopic transabdominal cerclage by using an atraumatic dissection of the tissue and a cerclage tape, needles removed. All patients were operated in a non-pregnant state and little complications were seen. It makes the laparoscopic TAC more simplified and safer than described by others $[1,5]$.

The transabdominal approach of cerclage in general (laparotomy and laparoscopy) is essential for adequate therapy in a select population of women. Probably the majority of patients in which it is decided to use cervical cerclage, can be helped with a transvaginal procedure. In this case the suture can be removed at 37 weeks, and a vaginal delivery can be aimed for.

The indications of placing a cerclage transabdominally

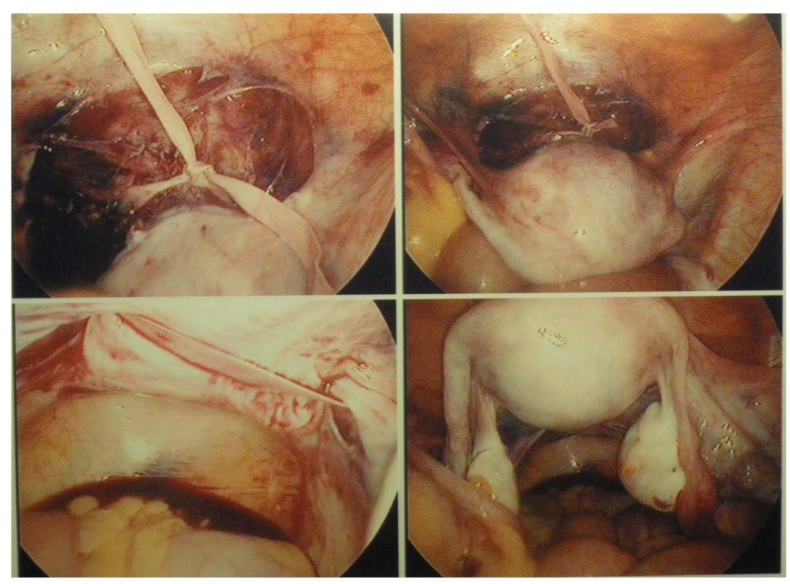

Figure 1. Peroperative view: the cerclage can be seen passing on the posterior side of the cervix, medially of the uterosacral ligaments with the knot on the anterior side.

are those individuals in whom a satisfactory transvaginal cerclage is not technically feasible: a congenital short or absent cervix, an extensively amputated cervix, marked scarring of the cervix and multiple deep cervical defects [1]. Also a previous failed vaginal cerclage has been regarded as a good indication for a TAC $[9,10]$. Some studies investigated the efficacy of a prophylactic cerclage after cervical conization for reducing the risk of preterm delivery. Despite the increased rate of preterm delivery ( $<34$ weeks) after conization, no benefit on the use of prophylactic cerclage can be found $[11,12]$.

Apart from the more complex technique of a TAC there are some advantages when using this technique instead of the TVC: high placement of the suture, no slippage of the cerclage, lack of a foreign body inside the vagina that could cause infection and preterm labour and the ability to leave the tape in place between pregnancies.

To use this technique laparoscopically the surgeon needs expertise in laparoscopic suturing. Compared with laparotomy, laparoscopy in general results in less or no hospitalization, less postoperative pain and faster recovery. A variation on this technique is the robotic-assisted laparoscopic TAC. This approach has the advantage of depth perception as well as dexterity because of greater than 500 degrees of motion $[13,14]$.

Mostly there is a choice of doing the procedure in a pregnant or a non-pregnant state. In the pregnant state, the cerclage is performed at the end of the first trimester (12 - 16 weeks) [15]. The advantage of operating in the nonpregnant state is the decrease in fetal and maternal risk, easy manipulation and exposure of the uterus and diminished risk of bleeding.

The most important complication of a TAC in general is excessive bleeding $[5,15]$. Doing this procedure in the non-pregnant state and using newer techniques of laparoscopic TAC this complication becomes rarer, but no 
data on the actual incidence are available. Another complication is the morbidity of the inevitable subsequent caesarean delivery. There are also the complications of the technique of a laparoscopy itself. Some of the reported complication after TVC, like rupture of the membranes, infection including chorioamnionitis and cervical dystocia are not seen in the laparoscopic TAC. Overall, one can say this minimal invasive technique has very little complications, but no large series are available.

The available literature consists of retrospective cohort studies or small case series. All the included studies in the table (Table 1) concern prophylactic cerclage either before or during pregnancy. No reports on emergency laparoscopic TAC have been published. In seven studies the operation was done in a pre-pregnant state, one retrospective cohort study [5] with 11 patients, five retrospective case series [1,16-19] with 2, 2, 2, 10 and 5 pa- tients and one case report [20]. In these studies all the pregnancies (the spontaneous losses before 12 weeks excluded) ended in delivery of a live born infant after 34 weeks by caesarean section. One retrospective cohort study described laparoscopic TAC during pregnancy (between $11-14$ weeks) and had an outcome of live born infants of $95 \%$, but only 20 pregnancies were included [21]. Also the 3 cases of a robotic-assisted placement of a TAC during pregnancy $[13,14]$ ended in delivery of a live born infant after 34 weeks. These results are comparable with retrospective cohort studies and case series of TAC by laparotomy.

Carter et al. [22] compared a prospective cohort of patients undergoing laparoscopic TAC with a historical control group of patients who underwent a laparotomy for TAC. In this small study (only 19 patients eligible for full evaluation) there was no difference in outcome for

Table 1. Outcome of studies concerning transabdominal cerclage by laparotomy and by laparoscopy.

\begin{tabular}{|c|c|c|c|c|c|}
\hline authors & type of study & $\begin{array}{c}\text { No. of } \\
\text { patients }\end{array}$ & technique used & time of placement & outcome \\
\hline Lotgering (2006) [15] & $\begin{array}{l}\text { observational cohort } \\
\text { study }\end{array}$ & 101 & $\begin{array}{l}\text { TAC }[\mathrm{a}] \text { by } \\
\text { laparotomy }\end{array}$ & during pregnancy & $\mathbf{9 3} \%$ deliveries $>32$ weeks \\
\hline Gesson-Paute (2006) [25] & retrospective case series & 12 & TAC by laparotomy & during pregnancy & $\mathbf{9 3} \%$ deliveries $>32$ weeks \\
\hline $\begin{array}{l}\text { Langhoff Thuesen (2009) } \\
\text { [26] }\end{array}$ & retrospective case series & 45 & TAC by laparotomy & before pregnancy & $\begin{array}{c}\mathbf{9 7} \% \text { deliveries }>34 \text { weeks } \\
\mathbf{1 0 0} \% \text { live born infants }\end{array}$ \\
\hline Umstad (2010) [27] & retrospective case series & 22 & TAC by laparotomy & $\begin{array}{c}\text { before and during } \\
\text { pregnancy }\end{array}$ & $\mathbf{9 1} \%$ deliveries $>34$ weeks \\
\hline Davis (2000) [9] & $\begin{array}{l}\text { retrospective cohort } \\
\text { study }\end{array}$ & 40 & TAC by laparotomy & during pregnancy & $\mathbf{9 0} \%$ deliveries $>33$ weeks \\
\hline Mingione (2003) [5] & $\begin{array}{l}\text { retrospective cohort } \\
\text { study }\end{array}$ & 11 & TAC by laparoscopy & before pregnancy & $\begin{array}{c}\mathbf{1 0 0} \% \text { deliveries }>34 \\
\text { weeks }\end{array}$ \\
\hline Al-Fadhli, Tulandi (2004) [1] & retrospective case series & 2 & TAC by laparoscopy & before pregnancy & $\begin{array}{c}\mathbf{1 0 0 \%} \text { deliveries }>34 \\
\text { weeks }\end{array}$ \\
\hline Kjollesdal (2005) [20] & retrospective case report & 1 & TAC by laparoscopy & before pregnancy & $\mathbf{1 0 0} \%$ term delivery \\
\hline Reid (2008) [17] & retrospective case series & 2 & TAC by laparoscopy & before pregnancy & $\begin{array}{c}\mathbf{1 0 0 \%} \text { deliveries }>34 \\
\text { weeks }\end{array}$ \\
\hline Liddell (2008) [18] & retrospective case series & 10 & TAC by laparoscopy & before pregnancy & $\begin{array}{l}\mathbf{1 0 0} \% \text { deliveries in third } \\
\text { trimester }\end{array}$ \\
\hline Nicolet (2009) [19] & retrospective case series & 5 & TAC by laparoscopy & before pregnancy & $\mathbf{1 0 0} \%$ term deliveries \\
\hline Chi-Heum Cho (2003) [21] & $\begin{array}{l}\text { retrospective cohort } \\
\text { study }\end{array}$ & 20 & TAC by laparoscopy & during pregnancy & $\mathbf{9 5 \%}$ live born infants \\
\hline Whittle (2009) [23] & prospective cohort study & 65 & TAC by laparoscopy & $\begin{array}{l}\text { before and during } \\
\text { pregnancy }\end{array}$ & $\begin{array}{c}\mathbf{8 9} \% \text { deliveries on } 35.8 \\
\text { weeks }+/-2.9 \text { weeks }\end{array}$ \\
\hline Fechner (2009) [14] & retrospective case report & 1 & TAC by RAL & during pregnancy & $\mathbf{1 0 0} \%$ delivery $>34$ weeks \\
\hline Carter (2009) [22] & prospective cohort study & 19 & 12 TAC laparoscopy & $\begin{array}{l}\text { before and during } \\
\text { pregnancy }\end{array}$ & $\begin{array}{l}\mathbf{7 5 \%} \text { viable pregnancy in } \\
\text { laparoscopy } \\
\mathbf{7 1 \%} \text { viable pregnancy in } \\
\text { laparotomy }\end{array}$ \\
\hline
\end{tabular}

[a] TAC: transabdominal cerclage; [b] RAL: robotic-assisted laparoscopy. 
viable pregnancies (75\% in laparoscopy and $71 \%$ in the laparotomy group). The authors conclude that laparoscopic transabdominal cerclage is an effective alternative to laparotomy in patients with a prior history of failed vaginal cerclage.

A comparable study design is seen in a study of Whittle et al. [23] with a much greater population. 65 patients underwent a laparoscopic TAC either before (34) or during (31) pregnancy. The outcomes were compared with the traditional laparotomy approach using previously reported cohorts. The laparoscopic TAC confers a similar rate of perioperative complications as the laparotomy and is best completed non-pregnant or in the first trimester. Excluding the first trimester losses the cerclage success in this study was $89 \%$ with a mean gestational age of $35.8+/-2.9$ weeks, which is a comparable obstetric outcome with the laparotomy approach.

There is one retrospective cohort study [9] which compared transabdominal and transvaginal prophylactic cerclage in a group of women with a failed vaginal cerclage in a previous pregnancy (patients with a cervix to short for transvaginal cerclage placement were excluded). They found a significant difference of $90 \%$ deliveries after 33 weeks in the TAC group and $62 \%$ in the TVC group.

But in general it is impossible and unreasonable to compare the outcome of TAC with transvaginal approach. Because of different indications, TAC is being limited to a select group of patients (see above). Despite of good results in some meta-analysis about the evidence of cerclage [24], overall the lack of clear diagnostic criteria for cervical insufficiency makes the indication of TVC questionable and the consequent outcome of studies impossible to compare.

Actually all published reports and series are too small to provide any evidence on the effectiveness of transabdominal laparoscopic cerclage and the outcome of following pregnancies, neither are such data available for transabdominal cerclage by laparotomy.

\section{Summary}

We describe a simplified technique for laparoscopic transabdominal cerclage for cervical insufficiency and give a review on the literature published on this subject. Transabdominal cerclage performed by laparoscopy seems to be an effective technique in cases transvaginal cerclage fails and is a good alternative for the laparotomic approach.

\section{REFERENCES}

[1] R. Al-Fadhli and T. Tulandi, "Laparoscopic Abdominal Cerclage," Obstetrics \& Gynecology Clinics of North America, Vol. 31, No. 3, 2004, pp. 497-504. doi:10.1016/j.ogc.2004.05.001

[2] A. J. Drakeley, D. Roberts and Z. Alfirevic, "Cervical
Cerclage for Prevention of Preterm Delivery: Meta-Analysis of Randomized Trials," Obstetrics \& Gynecology, Vol. 102, No. 3, 2003, pp. 621-627. doi:10.1016/S0029-7844(03)00673-2

[3] I. A. McDonald, "Suture of the Cervix for Inevitable Miscarriage," BJOG: An International Journal of Obstetrics \& Gynaecology, Vol. 64, No. 3, 1957, pp. 346-350. doi:10.1111/j.1471-0528.1957.tb02650.x

[4] R. C. Benson and R. B. Durfee, "Transabdominal Cervicouterine Cerclage for the Treatment of Cervical Incompetency," Obstetrics \& Gynecology, Vol. 25, No. 1, 1965, pp. 145-155.

[5] M. J. Mingione, J. J. Scibetta, S. R. Sanko and W. R. Phipps, "Clinical Outcomes Following Interval Laparoscopic Transabdominal Cervico-Isthmic Cerclage Placement: Case Series," Human Reproduction, Vol. 18, No. 8, 2003, pp. 1716-1719. doi:10.1093/humrep/deg345

[6] J. P. Geisler, C. J. Orr and K. J. Manahan, "Robotically Assisted Total Laparoscopic Radical Trachelectomy for Fertility Sparing in Stage IB1 Adenosarcoma of the Cervix," Journal of Laparoendoscopic \& Advanced Surgical Techniques A, Vol. 18, No. 5, 2008, pp. 727-729. doi:10.1089/lap.2007.0236

[7] J. Persson, P. Kannisto and T. Bossmar, "Robot-Assisted Abdominal Laparoscopic Radical Trachelectomy," Gynecologic Oncology, Vol. 111, No. 3, 2008, pp. 564-567. doi:10.1016/j.ygyno.2008.05.034

[8] Y. Sonoda and N. R. Abu-Rustum, "Radical Vaginal Trachelectomy and Laparoscopic Pelvic Lymphadenectomy for Early-Stage Cervical Cancer in Patients Who Desire to Preserve Fertility," Gynecologic Oncology, Vol. 104, No. 2, 2007, pp. 50-55. doi:10.1016/j.ygyno.2006.10.035

[9] G. Davis, V. Berghella, M. Talucci and R. J. Wapner, "Patients with a Prior Failed Transvaginal Cerclage: A Comparison of Obstetric Outcomes with Either Tansabdominal or Transvaginal Cerclage," American Journal of Obstetrics \& Gynecology, Vol. 183, No. 4, 2000, pp. 836839. doi: $10.1067 / \mathrm{mob} .2000 .108837$

[10] V. Zaveri, F. Aghajafari, K. Amankwah and M. Hannah, "Abdominal versus Vaginal Cerclage after a Failed Transvaginal Cerclage: A Systematic Review," American Journal of Obstetrics \& Gynecology, Vol. 187, No. 4, 2002, pp. 868-872. doi:10.1067/mob.2002.126959

[11] M. Y. Shin, E. S. Seo, S. J. Choi, S. Y. Oh, B. G. Kim, D. S. Bae, J. H. Kim and C. R. Roh, "The Role of Prophylactic Cerclage in Preventing Preterm Delivery after Electrosurgical Conization," Journal of Gynecologic Oncology, Vol. 21, No. 4, 2010, pp. 230-236. doi:10.3802/jgo.2010.21.4.230

[12] K. H. Nam, J. Y. Kwon, Y. H. Kim and Y. W. Park, "Pregnancy Outcome after Cervical Conization: Risk Factors for Preterm Delivery and the Efficacy of Prophylactic Cerclage," Journal of Gynecologic Oncology, Vol. 21, No. 4, 2010, pp. 225-229. doi:10.3802/jgo.2010.21.4.225

[13] L. Wolfe, S. De Pasquale, D. Adair, C. Torres, S. Stallings, C. Briery and C. Pearce, "Robotic-Assisted Laparoscopic Placement of Transbdominale Cerclage during Pregnancy," American Journal of Perinatology, Vol. 25, No. 10, 2008, pp. 653-655. doi:10.1055/s-0028-1090591 
[14] A. J. Fechner, M. Alvarez, D. H. Smith and A. Al-Khan, "Robotic-Assisted Laparoscopic Cerclage in a Pregnant Patient," American Journal of Obstetrics \& Gynecology, Vol. 200, No. 2, 2009, pp. 10-11. doi:10.1016/j.ajog.2008.10.029

[15] F. Lotgering, I. Gaugler-Senden, S. F. Lotgering and H. C. S. Wallenburg, "Outcome after Transabdominal Cervicoisthmic Cerclage," Obstetrics \& Gynecology, Vol. 107, No. 4, 2006, pp. 779-784. doi:10.1097/01.AOG.0000206817.97328.cd

[16] D. Gallot, D. Savary, H. Laurichesse, J. A. Bournazeau, J. Amblard and D. Lémery, "Experience with Three Laparoscopic Transabdominal Cervico-Isthmic Cerclage and Two Subsequent Pregnancies," BJOG: An International Journal of Obstetrics \& Gynaecology, Vol. 110, No. 7, 2003, pp. 696-700. doi:10.1046/j.1471-0528.2003.02272.x

[17] G. D. Reid, H. J. Wills, A. Shukla and P. Hammill, "Laparoscopic Transabdominal Cervico-Isthmic Cerclage: Minimally Invasive Approach," Australian \& New Zealand Journal of Obstetrics \& Gynaecology, Vol. 48, No. 2, 2008, pp. 185-188. doi:10.1111/j.1479-828X.2008.00835.x

[18] H. S. Liddell and C. Lo, "Laparoscopic Cervical Cerclage: A Series in Women with a History of Second Trimester Miscarriage," Journal of Minimally Invasive Gynecology, Vol. 15, No. 3, 2008, pp. 342-345. doi:10.1016/j.jmig.2008.01.003

[19] G. Nicolet, M. Cohen, L. Begue, L. Reyftmann, P. Boulot and H. Déchaud, "Laparoscopic Cervico-Isthmic Cerclage Evaluation," Gynécologie Obstétrique \& Fertilité, Vol. 37, No. 4, 2009, pp. 294-399. doi:10.1016/j.gyobfe.2009.02.012

[20] M. Kjollesdl, S. Nielsen, J.-H. Stjerndahl and M. A. Ellström Engh, "Laparoscopic Cervico-Uterine Cerclage Using Polypropylene Mesh for the Treatment of Cervical Incompetence," Acta Obstetricia et Gynecologica Scandinavica, Vol. 84, No. 8, 2005, pp. 823-824.
[21] C.-H. Cho, T.-H. Kim, S.-H. Kwon, J.-I. Kim, S.-D. Yoon and S.-D. Cha, "Laparoscopic Transabdominal Cerclage during Pregnancy," Journal of Minimally Invasive Gynecology, Vol. 10, No. 3, 2003, pp. 363-366.

[22] J. Carter, D. Soper, L. Goetzl and P. Van Dorsten, “Abdominal Cerclage for the Treatment of Recurrent Cervical Insuffficiency: Laparoscopy of Laparotomy?" American Journal of Obstetrics \& Gynecology, Vol. 201, No. 1, 2009, pp. 111.e1-111.e4.

[23] W. L. Whittle, S. S. Singh, L. Allen, L. Glaude, J. Thomas, R. Windrim and N. Leyland, "Laparoscopic Cervico-Isthmic Cerclage: Surgical Technique and Obstetric Outcomes," American Journal of Obstetrics \& Gynecology, Vol. 201, No. 4, 2009, pp. 364.e1-364.e7.

[24] V. Berghella, T. J. Rafael, J. M. Szychowski, O. A. Rust and J. Owen, "Cerclage for Short Cervix on Ultrasonography in Women with Singleton Gestations and Previous Preterm Birth: A Meta-Analysis," Obstetrics \& Gynecology, Vol. 117, No. 3, 2011, pp. 663-671. doi:10.1097/AOG.0b013e31820ca847

[25] A. Gesson-Paute, A. Berrebi and O. Parant, "Transabdominal Cervico-Isthmic Cerclage in the Management of Cervical Incompetence in High Risk Women," Journal de Gynécologie Obstétrique et Biologie de la Reproduction, Vol. 36, No. 1, 2007, pp. 30-35. doi:10.1016/j.jgyn.2006.11.003

[26] L. L. Thuezen, B. R. Diness and J. Langhoff-Roos, "PrePregnancy Transabdominal Cerclage," Acta Obstetricia et Gynecologica Scandinavica, Vol. 88, No. 4, 2009, pp. 483-486. doi:10.1080/00016340902730383

[27] M. P. Umstad, M. A. Quinn and A. Ades, "Transabdominal Cerclage," Austral and New Zealand Journal of Obstetrics and Gynaecology, Vol. 50, No. 5, 2010, pp. 460464. doi:10.1111/j.1479-828X.2010.01212.X 